\title{
Strategi Kesantunan Mata Najwa dalam episode Kami Bersama Novel
}

\author{
Riris Tiani \\ Fakultas Ilmu Budaya, Universitas Diponegoro, Semarang, Indonesia \\ tiani.riris@gmail.com
}

\begin{abstract}
Mata Najwa was the one of talkshow in Trans 7 which discuss about top topic in Indonesia. This research focuses on the direct speech which express at Mata Najwa "Kami Bersama Novel" at Trans 7. The purpose of this study is to describe and classify the form of compliance and infraction of the principle language politeness by Leech. The data source in this research are form of broadcast transcriptions which are divided into seven part which relate with research object. The research method used in this research is the method of referring with using the technique of note. The result of the study of compliance and infraction of the principle of politeness in this talkshow are eight compliance of the principle politeness, and six infraction of the principle politeness. This research found more compliance, because great image who have several figures, so it is able to be polite in conducting speeches.
\end{abstract}

Keywords: politeness, talkshow, speech.

\section{Intisari}

Mata Najwa merupakan salah satu talkshow yang ditayangkan oleh Trans 7 yang mengangkat topik yang sedang hangat di Indonesia. Penelitian ini memfokuskan pada tuturan langsung dalam tayangan Mata Najwa episode "Kami Bersama Novel" di Trans 7. Tujuan penelitian ini adalah untuk mendeskripsikan dan mengklasifikasi bentuk pematuhan dan pelanggaran prinsip kesantunan yang dikemukakan oleh Leech. Sumber data dalam penelitian ini berupa tranksripsi tayangan yang dibagi menjadi tujuh bagian yang masuk dalam kategori yang sesuai dengan tujuan penelitian. Metode penelitian yang digunakan adalah metode simak dengan teknik catat. Hasil dari penelitian ini adalah ditemukan delapan pematuhan maksim kesantunan, dan enam pelanggaran maksim kesantunan. Dalam penelitian ini ditemukan lebih banyak pematuhan prinsip kesantunan, karena image baik yang dimiliki para tokoh, sehingga lebih mampu untuk santun dalam melakukan pertuturan.

Kata Kunci: Kesantunan, talkshow, tuturan.

\section{Pendahuluan}

Televisi adalah salah satu media elektronik yang populer di masyarakat Indonesia. Televisi tidak hanya digunakan masyarakat untuk mengisi waktu senggang, tetapi juga dimanfaatkan masyarakat untuk mendapatkan informasi yang aktual. Dewasa ini, banyak orang tidak dapat terlepas dari penggunaan televisi. Televisi memegang peranan penting 
dalam masyarakat, tetapi terkadang hal tersebut menjadi sebuah perdebatan. Media ini memliki banyak manfaat yang berpengaruh bagi masyarakat, namun tak sedikit pula efek negatif yang ditimbulkannya.

Bahasa adalah salah satu komponen dalam suatu penyiaran di televisi. Penggunaan bahasa di televisi ini memiliki banyak pengaruh bagi masyarakat. Dalam kehidupan manusia, bahasa mempunyai peran yang penting sebagai alat komunikasi yang merupakan suatu pemenuhan kebutuhan manusia untuk berinteraksi dengan sesama. Ketika berkomunikasi, seorang penutur harus mampu menyampaikan ide dan gagasannya sehingga mampu diterima oleh mitra tuturnya. Pemilihan bahasa yang tepat dalam hal ini juga mempengaruhi.

Bahasa memiliki etika yang tidak tertulis mengenai kesantunan. Dalam praktiknya pada kehidupan manusia, kesantunan berbahasa terkadang tidak dipatuhi dalam proses komunikasi sehari-hari, baik secara langsung maupun tidak langsung. Berbahasa santun dan berperilaku santun agaknya memang dibutuhkan oleh setiap orang dalam melakukan sebuah pertuturan. Seseorang dapat berbahasa dan berperilaku santun dimaksudkan sebagai wujud aktualisasi diri (Pranowo dalam Ramadhan, 2017:2).

Pragmatik sebagai retorika tekstual membutuhkan prinsip kerja sama, namun sebagai retorika interpersonal pragmatik membutuhkan prinsip lain yakni prinsip kesopanan. Leech memandang prinsip kesantunan sebagai 'piranti' untuk menjelaskan mengapa penutur sering bertutur secara tidak langsung dalam mengungkapkan maksudnya. Penggunaan tindak tutur tidak langsung bertujuan agar ujaran terdengar santun. Penutur menggunakan implikatur dalam tuturannya (Pranowo, 2009). Tarigan dalam Rahardi (2005) mengemukakan prinsip kesantunan Leech ke dalam enam macam maksim meliputi: maksim kebijaksanaan, kedermawanan, penghargaan, kesederhanaan, pemufakatan, dan maksim kesimpatian.

Mata Najwa merupakan salah satu program talkshow yang ditayangkan oleh Trans 7 dan dipandu oleh seorang jurnalis yang cerdas yakni Najwa Shihab. Acara ini menghadirkan tokoh-tokoh yang berkaitan dengan topik-topik yang sedang hangat di negeri ini. Pada 28 Februari 2018, Mata Najwa mengangkat topik mengenai penyiraman air keras yang menimpa salah satu penyidik KPK yakni Novel Baswedan. Dalam acara tersebut banyak menghadirkan beberapa tokoh penting terkait dengan kasus tersebut. 
Menariknya, kasus ini belum dapat diungkap hingga saat ini yang berarti sudah lebih dari dua tahun berjalan dan penyidik belum mampu mengungkap pelaku dibaliknya.

Tuturan antara Najwa Shihab dengan beberapa tokoh terdapat hal yang membicarakan fakta atau kebohongan, melebih-lebihkan, dan atau mengangkat hal yang sifatnya hanya menjaga harga diri penutur maupun mitra tutur. Hal ini berkaitan dengan prinsip kesantunan berbahasa. Peneliti mengkaji objek berdasarkan prinsip kesantunan berbahasa yang dikemukakan oleh Leech. Sehingga, dalam penelitian ini akan diuraikan mengenai pematuhan dan pelanggaran prinsip kesantunan dalam tayangan Mata Najwa episode 'Kami Bersama Novel'.

\section{Metode Penelitian}

Permasalahan yang dikaji dalam penelitian ini adalah strategi kesantunan yang terdapat dalam tayangan Mata Najwa episode "Kami Bersama Novel" di Trans 7 yang diunggah pada akun youtube 'Najwa Shihab' pada 28 Februari 2018. Peneliti membagi metode penelitian ini atas tiga tahapan, yaitu penyediaan data, analisis data, dan penyajian hasil analisis data (Sudaryanto, 1993).

Pada tahap penyediaan data penulis mengakses akun youtube Najwa Shihab yang memposting tentang acara 'Mata Najwa' dengan episode "Kami Bersama Novel" kemudian menyimak secara saksama tiap bagian tayangan yang dalam hal ini dibagi menjadi tujuh bagian. Kemudian, penulis mentranskripsikan tiap tayangan untuk selanjutnya dilakukan analisis. Tahap analisis menggunakan pendekatan kontekstual fenomenologis, yakni mendeskripsikan data yang ada sesuai denga situasi kebahasaan yang ada, barulah disimpulkan menggunakan bentuk paraphrase verbal.

\section{Hasil dan Pembahasan}

\section{Maksim Kebijaksanaan}

Data 1

Konteks : Najwa menunggu Novel yang sedang keluar dari masjid usai shalat subuh, lalu menyapa Novel dan kemudian mengajak Novel untuk berbincang sambal berjalan menuju rumahnya.

Najwa Shihab : "Bang Novel keberatan tidak kalau saya meminta untuk bercerita apa yang ketika itu terjadi persisnya sambil kita menyusuri jalanan ini, Bang?" 
Novel Baswedan : "Iya. Ee saya masih ingat betul, saya pulang dari sholat subuh di tempat mbak Najwa tadi berdiri. Di situ saya sempat berbincang dengan tetangga yang sudah selesai shalat terlebih dahulu, dan kemudian saya berjalan menuju ke arah rumah kurang lebih 20 meter di depan itu saya diikuti oleh kendaraan dan kemudian disiram air keras di situ, kurang lebih begitu."

Tuturan yang dikatakan Najwa Shihab merupakan pematuhan maksim kebijaksanaan. Hal tersebut dapat dibuktikan pada pemarkah 'keberatan tidak kalau saya meminta untuk bercerita apa yang ketika itu terjadi persisnya?'. Maksim ini mengharapkan peserta tutur untuk mengurangi keuntungan pada dirinya sendiri, dan memaksimalkan keuntungan bagi pihak lain dalam kegiatan bertutur. Pada kata 'keberatan tidak' berarti Najwa Shihab tidak memaksa dan meminta persetujuan terlebih dahulu kepada Novel Baswedan untuk menceritakan mengenai peristiwa penyiraman air keras yang menimpanya.

Data 2

Konteks : Najwa bertanya kepada Agus Rahardjo selaku ketua KPK mengenai pembentukan Tim Gabungan Pencari Fakta untuk mengungkap kasus penyiraman air keras kepada Novel Baswedan.

Najwa Shihab : "Berarti seharusnya tidak masalah juga KPK mendorong spesifik meminta presiden untuk itu, toh tidak ada yang perlu ditakuti kan?"

Agus Rahardjo : "Iya tidak ada yang perlu ditakuti. Jadi.."

Najwa Shihab : "Tetapi dorongan itu KPK belum kenapa hanya menyerahkan ke presiden? Apakah Anda tidak melihat ini simbol, ketika KPK pimpinannya yang meminta spesifik itu akan menjadi dorongan yang lebih powerfull dibandingkan dengan hanya ee bukan hanya ya saya merasa kekuatan masyarakat pasti luar biasa. Tetapi kalau kemudian KPK berdiri paling depan untuk meminta hal yang sama, bukankah ini akan menjadi suatu pendorong yang maksimal?"

Tuturan yang dikatakan Najwa Shihab pada data di atas merupakan pelanggaran maksim kebijaksanaan. Hal tersebut dapat dibuktikan saat Najwa Shihab bertanya kepada Agus Rahardjo mengenai KPK yang harusnya mendorong presiden untuk segera membentuk TGPF, kemudian Agus Rahardjo menjawab pertanyaan Najwa. Tetapi, ketika Agus Rahardjo belum selesai menjawab, Najwa Shihab sudah memotong tuturan Agus Rahardjo dengan memberi pertanyaan kembali. Maksim kebijaksanaan mengharapkan peserta tutur untuk mengurangi keuntungan pada dirinya sendiri, dan 
memaksimalkan keuntungan bagi pihak lain dalam kegiatan bertutur. Pemberian pertanyaan kembali oleh Najwa Shihab kepada Agus Rahardjo ketika Agus Rahardjo belum selesai menjawab pertanyaan sebelumnya dikatakan melanggar maksim kebijaksanaan, karena penutur tidak memberikan keuntungan yang dalam hal ini berupa kesempatan untuk menyelesaikan jawaban atas pertanyaan terdahulu kepada mitra tutur sehingga penutur terkesan kurang menghargai mitra tutur.

Data 3

Konteks : Najwa Shihab menayangkan CCTV terkait dengan sebelum penyerangan dan saat penyerangan kasus Novel, kemudian meminta tanggapan Argo Yuwono selaku Kabid Humas Polda Metro Jaya.

Najwa Shihab : "Yang tadi kita saksikan sama-sama adalah CCTV yang pertama adalah CCTV yang terjadi sebelum penyerangan ada diduga seseorang yang memata-matai rumah Novel Baswedan, dan yang kedua adalah CCTV pada saat penyerangan diduga setelah Novel Baswedan disiram air keras dan kemudian tadi kita lihat ada motor yang berusaha melalui dua orang jamaah yang baru pulang dari masjid. Polisi tidak mau menuntaskan kasus ini?"

Argo Yuwono : “Apapun ceritanya, Novel itu kan mantan polisi. Itu jadi bagian dari keluarga besar polisi disitu ya, tentunya polisi tadi komitmen yang pertama saya sampaikan. Kita akan berupaya mencari bukti-bukti, saksi-saksi, jadi jangan sampai asumsi yang muncul disitu atau katanya-katanya. Tapi kita ingin membuktikan bahwa ada fakta hukum yang jelas di situ."

Tuturan yang dikatakan oleh Argo Yuwono pada data di atas merupakan pematuhan maksim kebijaksanaan. Hal tersebut dibuktikan pada pemarkah 'Novel itu kan mantan polisi. Itu jadi bagian dari keluarga besar polisi disitu ya' yang berarti Argo Yuwono menganggap bahwa Novel Baswedan masih memiliki kedekatan sebagai keluarga dari kepolisian, yang terkait dengan pertanyaan Najwa Shihab sebelumnya yakni mengenai apakah polisi tidak mau menuntaskan kasus yang dialami Novel. Dan pemarkah 'Kita akan berupaya mencari bukti-bukti, saksi-saksi, jadi jangan sampai asumsi yang muncul disitu atau katanya-katanya' yang berarti bahwa Argo Yuwono menanggapi pertanyaan Najwa Shihab dengan jawaban yang logis disertai alasan yang mendukung, dengan kata-kata yang santun.

\section{Maksim Kesederhanaan}


Data 4

Konteks : Najwa Shihab bertanya kepada Novel Baswedan mengenai kegiatan yang biasa dilakukan Novel ketika waktu subuh.

Najwa Shihab : "Singkatnya seperti itu. Ini memang rutinitas yang sehari-hari bang Novel lakukan? Pagi ke masjid setiap subuh? Jadi itu memang kegiatan yang orang dengan mudah akan tahu pasti subuh-subuh Novel Baswedan akan shalat di masjid yang tak jauh dari rumah. Begitu ya, Bang?"

Novel Baswedan : "Ya, sepanjang di rumah begitu insyaAllah."

Tuturan yang dikatakan Novel Baswedan merupakan pematuhan maksim kesederhanaan. Maksim ini mengharapkan peserta tutur untuk dapat bersikap rendah hati dengan cara mengurangi pujian terhadap dirinya sendiri. Hal tersebut dapat dibuktikan pada tuturan Novel Baswedan atas pertanyaan Najwa Shihab. Dalam data tersebut, Novel Baswedan hanya menjawab dengan tuturan yang sederhana dengan mengiyakan pertanyaan Najwa Shihab tanpa mengatakan tuturan berlebih yang bersifat memuji dirinya sendiri.

Data 5

Konteks : Najwa bertanya kepada Agus mengenai peran Agus sebagai ketua KPK untuk meminta kepada presiden terkait dengan pembentukan TGPF.

Najwa Shihab : "Tetapi dorongan itu KPK belum kenapa hanya menyerahkan ke presiden? Apakah Anda tidak melihat ini simbol, ketika KPK pimpinannya yang meminta spesifik itu akan menjadi dorongan yang lebih powerfull dibandingkan dengan hanya ee bukan hanya ya saya merasa kekuatan masyarakat pasti luar biasa. Tetapi kalau kemudian KPK berdiri paling depan untuk meminta hal yang sama, bukankah ini akan menjadi suatu pendorong yang maksimal?"

Agus Rahardjo : "Bisa jadi seperti itu. Tetapi sekali lagi, sikap dari awal kalaupun saya berbicara seperti ini kan kemudian seperti Anda ketahui itu bukan suara saya sendiri kan. Kita kan selalu saya tekankan di KPK itu bukan Agus Rahardjo istilahnya di KPK itu berlima. Jadi keputusannya yang diambil waktu itu memang kita kemudian menyerahkan sepenuhnya kepada presiden, kemudian kami harapkan kebijakan presiden kebijaksanaan presiden kemudian bisa melihat itu. Jadi kalau kasusnya tidak tuntas ya tanpa ditekan siapapun, presiden mestinya mengambil keputusan itu."

Tuturan Agus Rahardjo pada data di atas merupakan pematuhan maksim kesederhanaan. Hal tersebut dibuktikan pada tuturan Agus Rahardjo yang mengatakan 
bahwa walaupun dia mempunyai posisi sebagai ketua KPK, tapi dalam menentukan sebuah keputusan tetap ditentukan oleh pemufakatan bersama dengan anggota yang lain. Maksim kesederhanaan mengharapkan peserta tutur untuk dapat bersikap rendah hati dengan cara mengurangi pujian terhadap dirinya sendiri. Dalam tuturan di atas, Najwa Shihab menekankan bahwa posisi Agus Rahardjo adalah sebagai ketua yang mempunyai kewenangan lebih untuk menentukan sebuah keputusan. Tetapi, Agus Rahardjo menjawab pertanyaan Najwa Shihab dengan rendah hati, bahwa ia tidak menyombongkan dirinya yang berkedudukan sebagai ketua. Jadi, walaupun ia berposisi sebagai ketua, saat pengambilan keputusan tidak semata-mata bertumpu pada keinginannya tetapi melalui pemufakatan bersama dengan anggota KPK yang lain yang disebutkan pada tuturan Agus Rahardjo.

\section{Maksim Penghargaan atau Penerimaan}

Data 6

Konteks : Najwa Shihab bertanya mengenai keadaan mata Novel Baswedan setelah beberapa bulan menjalani perawatan di Singapura.

Najwa Shihab : "Bang Novel, saya ingat terakhir ketika kita berbincang bulan Juli waktu itu bang Novel bercerita bahwa kondisi mata kiri kurang lebih 95-97\% kerusakannya dan mata kanan 60\%. Kondisi sekarang setelah hampir sepuluh bulan menjalani perawatan?"

Novel Baswedan : "Begini, alhamdulillah setelah dilakukan perawatan oleh dokter, mata kanan saya sudah tertutup selaput secara keseluruhan. Kalau bicara persentase menjadi agak sulit karena selaput yang menutup di mata kanan saya itu sedikit bergelombang ditambah ada bercak putih di beberapa tempat yang membuat pandangan saya blur seperti sekarang, kabur ya. Jadi, saya melihat jarak beberapa meter ke depan lihat wajah nggak jelas."

Tuturan yang dikatakan Novel Baswedan pada data di atas merupakan pematuhan maksim penghargaan atau penerimaan. Hal tersebut dapat ditunjukkan pada pemarkah 'begini, alhamdulillah setelah dilakukan perawatan oleh dokter, mata kanan saya sudah tertutup selaput secara keseluruhan' yang berarti Novel Baswedan menerima keadaan yang dialaminya. Dalam maksim ini, seseorang akan dianggap santun apabila dalam bertutur selalu berusaha memberikan penghargaan kepada pihak lain. Dalam tuturan tersebut, Novel Baswedan kemudian juga menceritakan tentang kondisi matanya yang sudah sedikit membaik setelah ia menjalankan perawatan.

Data 7 
Konteks : Najwa Shihab bertanya kepada Novel Baswedan mengenai perkembangan penyidikan terhadap kasus yang menimpa Novel Baswedan.

Najwa Shihab : "Sejauh ini, proses penyelidikan yang dilakukan oleh kepolisian. Bagaimana bang Novel Baswedan melihat perkembangannya? Atau karena memang tidak ada perkembangannya jadi tidak ada yang bisa dikomentari?"

Novel Baswedan: "Yang pertama, sampai sekarang saya memang belum pernah menerima laporan perkembangan penyidikan. Kemarin penyidik ketika datang ke sini, saya appreciate sekali kepada mereka bahwa penyidik mau komunikasi dengan saya dengan baik dan memberikan perhatian."

Tuturan yang dikatakan Novel Baswedan pada data di atas merupakan pematuhan maksim penghargaan. Hal tersebut dibuktikan pada pemarkah 'saya appreciate sekali kepada mereka bahwa penyidik mau komunikasi dengan saya dengan baik dan memberikan perhatian'. Dalam maksim ini, seseorang akan dianggap santun apabila dalam bertutur selalu berusaha memberikan penghargaan kepada pihak lain. Pada kata 'saya appreciate sekali kepada mereka' berarti Novel Baswedan memberi apresiasi dan menghargai upaya baik yang dilakukan penyidik yang dalam hal ini merupakan pihak lain dalam menangani kasusnya.

\section{Maksim Kesimpatisan}

Data 8

Konteks : Najwa Shihab bertanya duduk berbincang di kediaman Novel Baswedan, dan kemudian bertanya mengenai perkembangan penyelidikan kasus Novel oleh kepolisian.

Najwa Shihab : "Sejauh ini, proses penyelidikan yang dilakukan oleh kepolisian. Bagaimana bang Novel melihat perkembangannya? Atau karena memang tidak ada perkembangannya jadi tidak ada yang bisa dikomentari?"

Novel Baswedan: "Yang pertama, sampai sekarang saya memang belum pernah menerima laporan perkembangan penyidikan. Kemarin penyidik ketika datang ke sini, saya appreciate sekali kepada mereka bahwa penyidik mau komunikasi dengan saya dengan baik dan memberikan perhatian."

Tuturan yang dikatakan oleh Najwa Shihab pada data di atas merupakan pelanggaran maksim kesimpatisan. Hal tersebut dibuktikan pada pemarkah 'Atau karena memang tidak ada perkembangannya jadi tidak ada yang bisa dikomentari?'. Dalam maksim ini, mengharapkan peserta pertuturan untuk memaksimalkan rasa simpati, dan meminimalkan rasa antipati terhadap lawan tuturnya. Pada kata 'atau karena memang 
tidak ada perkembangannya' berarti Najwa Shihab dalam hal ini kurang bersimpati terhadap apa yang menimpa Novel Baswedan, walaupun pada tuturan tersebut Najwa Shihab bertanya kepada Novel Baswedan. Tetapi, agaknya pada kata tersebut di atas dirasa kurang santun diucapkan ketika bertanya.

Data 9

Konteks : Najwa Shihab bertanya kepada Novel Baswedan mengenai perkembangan penyidikan kasus yang dialami Novel.

Novel Baswedan : "Ya sangat perlu karena apakah kita akan mengabaikan penyerangan ini? Kalau kita abaikan ya sudah nggak usah dibentuk tim gabungan pencari fakta. Tapi kalau kita menganggap bahwa ini penting untuk diungkap, maka pak presiden mestinya mengupayakan untuk membentuk. Saya kemarin mendengar dari rekan bahwa di media, pak presiden menyampaikan bahwa akan dibentuk tim lain. Saya nggak paham maksutnya kemana, barangkali beliau punya pertimbangan yang strategis yang tentunya itu lebih baik, saya nggak paham. Cuman memang kalau dibentuk tim tertentu, setidaknya tim itu akan membantu tugas-tugas penyidik POLRI, yang dengan begitu pengungkapannya menjadi lebih punya harapan."

Najwa Shihab : "Dibanding sekarang yang tampaknya tidak ada harapan?"

Novel Baswedan : "Saya menduga begitu."

Tuturan yang dikatakan oleh Najwa Shihab pada data di atas merupakan pelanggaran maksim kesimpatisan. Hal tersebut dibuktikan pada pemarkah 'tampaknya tidak ada harapan'. Maksim ini mengharapkan peserta tutur untuk memaksimalkan rasa simpati dan meminimalkan rasa antipati dalam kegiatan bertutur. Tuturan Najwa Shihab pada data tersebut dikatakan melanggar maksim kesimpatisan karena Najwa Shihab dalam tuturannya tidak menunjukkan rasa simpati terhadap kasus Novel Baswedan, dalam hal ini Najwa Shihab malah memberi pertanyaan balik kepada Novel Baswedan yang mengatakan bahwa seakan-akan kasus Novel Baswedan nampak tidak ada harapan untuk terungkap pelakunya.

Data 10

Konteks : Najwa Shihab bertanya kepada Tama selaku aktivis ICW terkait pendapatnya mengenai kasus penyiraman air keras yang menimpa Novel Baswedan.

Najwa Shihab : "Kami Bersama Novel Baswedan, dan kami menolak takut. Saya ingin ke aktivis ICW yang juga pernah menjadi korban waktu itu, yang sampai sekarang kasusnya belum terselesaikan. Tama, apa refleksi Anda atas apa yang terjadi pada Novel Baswedan? Apa yang seharusnya menjadi catatan penting?" 
Tama S. Langkun : "Ya menurut saya ini akan menjadi hal-hal yang terus berulang sepanjang perkaranya tidak pernah selesai. Soal Novel misalnya, soal serangan kepada Novel, ini kan bukan yang pertama. Kalau kita mau hitung-hitung itu banyak sekali, yang ditabrak saja itu tiga kali ditabrak, dua kali berhasil, satu kali lolos. Nah ini kan kita juga nggak pernah tau misalnya, apa atau bagaimana nasib terhadap orang yang menabrak. Kalau kemudian itu dibiarkan saja nggak ada jawaban, besoknya ditabrak lagi nanti. Begitu juga dengan yang menyiram air keras kepada Novel, kalau kemudian itu nggak diungkap, dibiarkan, besok akan begitu lagi. Bahkan..”

Tuturan yang dikatakan oleh Tama pada data di atas merupakan pelanggaran maksim kesimpatisan. Hal tersebut dibuktikan pada pemarkah 'ya menurut saya ini akan menjadi hal-hal yang terus berulang sepanjang perkaranya tidak pernah selesai'. Maksim kesimpatisan mengharapkan peserta tutur untuk memaksimalkan rasa simpati dan meminimalkan rasa antipati dalam kegiatan bertutur. Pada kata 'akan menjadi halhal yang terus berulang' disini berarti Tama kurang memberikan simpati terhadap kasus Novel. Tuturan yang dikatakan Tama seolah-olah berbicara bahwa aka nada banyak kasus serupa yang menimpa anggota KPK yang lain. Sehingga, tuturan tersebut dinilai kurang santun karena seharusnya Tama melalui tanggapannya memberikan simpati terhadap kasus Novel dan berharap agar penyidik dapat mengungkap kasus tersebut secara tuntas, dan tidak ada lagi korban dengan kasus yang serupa.

\section{Maksim Kedermawanan}

Data 11

Konteks : Najwa bertanya kepada Novel mengenai perkembangan penyidikan kasus yang menimpanya, sehubungan dengan digantinya penyidik yang menangani kasus Novel.

Najwa Shihab : “Apa yang terlintas di benak Anda ketika bahkan penyidiknya pun diganti oleh kepolisian?"

Novel Baswedan : "Ya saya tidak ingin larut dalam pemikiran yang seperti itu. Saya kira saya berfikir secara umum saja bahwa memang dari awal saya menduga bahwa ini tidak akan diungkap dengan optimal, tidak diungkap dengan serius."

Tuturan yang dikatakan Novel Baswedan pada data di atas merupakan pelanggaran maksim kedermawanan. Hal tersebut dibuktikan pada pemarkah 'saya menduga bahwa ini tidak akan diungkap dengan optimal, tidak diungkap dengan serius'. Maksim ini mengharapkan agar peserta percakapan menghormati orang lain. Pada kata 'ini tidak akan diungkap dengan optimal' berarti Novel Baswedan berfikir bahwa kasus yang 
dialaminya tidak akan terungkap siapa pelakunya atau secara tidak langsung penyidik tidak akan mengungkap atau menyembunyikan pelaku dari kasus ini. Hal tersebut merupakan pelanggaran maksim kedermawanan, karena tuturan yang dikatakan oleh Novel Baswedan dapat dikatakan tidak menghormati orang lain yang dalam hal ini adalah penyidik.

\section{Maksim Pemufakatan}

Data 12

Konteks : Najwa Shihab bertanya kepada Novel Baswedan mengenai penyidikan kasus yang dialami Novel yang tak kunjung terungkap, kemudian Najwa bertanya mengenai pembentukan TGPF untuk membantu pengungkapan kasus.

Najwa Shihab : "Karnanya, koalisi untuk KPK, kemudian teman-teman kuasa hukum dan beberapa tokoh-tokoh mendesak agar dibentuk Tim Gabungan Pencari Fakta, karena merasa bahwa harus tim inilah yang mengungkap kasus ini melihat polisi belum menunjukkan adanya perkembangan yang signifikan. Itu sesuatu yang menurut Anda sangat perlu dilakukan?"

Novel Baswedan : "Ya sangat perlu karena apakah kita akan mengabaikan penyerangan ini? Kalau kita abaikan ya sudah nggak usah dibentuk tim gabungan pencari fakta. Tapi kalau kita menganggap bahwa ini penting untuk diungkap, maka pak presiden mestinya mengupayakan untuk membentuk. Saya kemarin mendengar dari rekan bahwa di media, pak presiden menyampaikan bahwa akan dibentuk tim lain. Saya nggak paham maksutnya kemana, barangkali beliau punya pertimbangan yang strategis yang tentunya itu lebih baik, saya nggak paham. Cuman memang kalau dibentuk tim tertentu, setidaknya tim itu akan membantu tugas-tugas penyidik POLRI, yang dengan begitu pengungkapannya menjadi lebih punya harapan."

Tuturan yang dikatakan oleh Novel Baswedan pada data di atas merupakan pematuhan maksim kecocokan. Hal tersebut dibuktikan pada pemarkah 'ya sangat perlu' yang berarti Novel Baswedan menyetujui tentang apa yang dikatakan oleh Najwa Shihab sebelumnya. Maksim ini mengharapkan kepada peserta tutur agar dapat saling membina kecocokan dalam kegiatan bertutur. Tuturan Najwa Shihab pada data di atas adalah mengenai pertanyaan atas tanggapan Novel Baswedan sebelumnya yang mengatakan bahwa kasusnya tidak akan diungkap dengan optimal, kemudian Najwa Shihab berbalik bertanya kepada Novel Baswedan mengenai apakah perlu pembentukan tim gabungan pencari fakta sehubungan dengan penyidikan kasus Novel yang tidak menghasilkan perkembangan yang signifikan. Lalu, Novel Baswedan menjawab tuturan Najwa Shihab 
dengan setuju terhadap apa yang dikatakan oleh Najwa beserta alasan yang mendukung.

Sehingga, antara penutur dan mitra tutur memiliki kecocokan dalam pertuturan.

Data 13

Konteks : Najwa Shihab bertanya kepada Agus Rahardjo mengenai kasus penyiraman air keras terhadap Novel Baswedan yang menurutnya penyerangan tersebut bukan hanya ditujukan kepada Novel tetapi kepada pihak yang menangani pemberantasan korupsi.

Najwa Baswedan: " Pak Agus ini serangan bukan hanya ke Novel tetapi harus dilihat sebagai serangan terhadap upaya pemberantasan korupsi secara keseluruhan. Anda sependapat?"

Agus Rahardjo : "Sependapat. Jadi memang kalau kita melihat ini rangkaian yang sebetulnya bukan hanya kepada saudara Novel, sebagaimana kita ketahui juga ada pansus yang berjalan, kemudian yang diancam dan diserang itu juga bukan hanya saudara Novel, adik-adik di KPK juga banyak. Oleh karena itu, saya sangat berharap memang kasus ini harus tuntas, kasus ini harus bisa diselesaikan. Oleh karena itu, temen-temen POLRI kemudian harus memulai betul-betul memusatkan perhatiannya, terlebih kalau kemudian melihat ini ya kemudian seperti saya sampaikan dalam pembicaraan sebelumnya bahwa bapak presiden harus mengambil kebijakan yang sebaik-baiknya, kami serahkan kepada pak presiden untuk kemudian melihat suara ini kemudian mempertimbangkan beliau dan mengambil langkah-langkah yang cukup penting untuk melindungi gerakan anti korupsi yang kita dengungkan."

Tuturan yang dikatakan oleh Agus Rahardjo dalam data di atas merupakan pematuhan maksim kecocokan. Hal tersebut dibuktikan pada pemarkah 'sependapat' yang berarti Agus Rahardjo menyetujui tentang apa yang dikatakan oleh Najwa Shihab sebelumnya. Maksim ini mengharapkan kepada peserta tutur agar dapat saling membina kecocokan dalam kegiatan bertutur. Tuturan yang dikatakan Najwa Shihab adalah mengenai tanggapan Tama S. Langkun yakni seorang aktivis ICW yang berpendapat bahwa kasus penyerangan ini yang menjadi sasarannya bukan hanya Novel Baswedan saja, melainkan kasus tersebut merupakan ancaman terhadap aparat penegak pemberantasan korupsi, lalu Najwa Shihab bertanya mengenai pendapat Tama tersebut kepada Agus. Agus kemudian menjawab tuturan Najwa dengan setuju terhadap apa yang dikatakan oleh Najwa Shihab beserta alasan-alasan yang mendukung. Tuturan tersebut dapat dikatakan mematuhi maksim kecocokan, karena antara penutur dan mitra tutur memiliki kecocokan dalam pertuturan.

\section{Simpulan}


Berdasarkan hasil pembahasan di atas, dapat disimpulkan bahwa dalam tayangan Mata Najwa episode "Kami Bersama Novel" terdapat delapan tuturan yang memenuhi prinsip kesantunan. Tuturan yang memenuhi prinsip kesantunan yakni dua maksim kebijaksanaan, dua maksim kesederhanaan, dua maksim penerimaan, dua maksim kedermawanan, dan dua maksim kecocokan. Selain itu, pada tayangan tersebut juga ditemukan terdapat enam pelanggaran prinsip kesantunan. Tuturan yang melanggar prinsip kesantunan yakni satu maksim kebijaksanaan, tiga maksim kesimpatisan, dan dua maksim kedermawanan. Sehingga, dapat disimpulkan bahwa tayangan Mata Najwa episode "Kami Bersama Novel" lebih dominan terhadap pemenuhan prinsip kesantunan. Hal ini disebabkan karena image baik yang dimiliki para tokoh, sehingga lebih mampu untuk santun dalam melakukan pertuturan.

\section{Daftar Pustaka}

Pranowo. 2009. Berbahasa Secara Santun. Yogyakarta: Pustaka Pelajar

Rahardi, R. Kunjana. 2005. Pragmatik: Kesantunan Imperatif Bahasa Indonesia. Jakarta: Erlangga

Sudaryanto. 1993. Metode dan Teknik Analisis Bahasa Pengantar Wacana Wahana Kebudayaan Secara Linguistik. Yogyakarta: Duta Wacana University Press 